\title{
CORRECTION
}

\section{Correction: Janus-faced EPHB4-associated disorders: novel pathogenic variants and unreported intrafamilial overlapping phenotypes}

Silvia Martin-Almedina (D), Kazim Ogmen (ID), Ege Sackey (D), Dionysios Grigoriadis (D), Christina Karapouliou (D), Noeline Nadarajah, Cathrine Ebbing (D), Jenny Lord (D), Rhiannon Mellis (D), Fanny Kortuem, Mary Beth Dinulos (iD, Cassandra Polun, Sherri Bale, Giles Atton, Alexandra Robinson (iD), Hallvard Reigstad (D), Gunnar Houge (D), Axel von der Wense, Wolf-Henning Becker, Steve Jeffery (D),

Peter S. Mortimer (ID, Kristiana Gordon (D), Katherine S. Josephs (ID), Sarah Robart, Mark D. Kilby (D), Stephanie Vallee, Jerome L. Gorski, Maja Hempel (D), Siren Berland (D), Sahar Mansour (iD) and Pia Ostergaard (D)

Genetics in Medicine (2021) 23:1376-1377; https://doi.org/10.1038/s41436-021-01202-0

Correction to: Genetics in Medicine 2021; https://doi.org/10.1038/ s41436-021-01136-7; published online 16 April 2021

Due to a processing error, the ESM was incomplete. The complete ESM is given on https://doi.org/10.1038/s41436-021-01136-7.

Unfortunately an error occurred in Fig. 1a. The corrected Fig. 1 is given below:

The original article has been corrected.

Open Access This article is licensed under a Creative Commons Attribution 4.0 International License, which permits use, sharing, adaptation, distribution and reproduction in any medium or format, as long as you give appropriate credit to the original author(s) and the source, provide a link to the Creative Commons license, and indicate if changes were made. The images or other third party material in this article are included in the article's Creative Commons license, unless indicated otherwise in a credit line to the material. If material is not included in the article's Creative Commons license and your intended use is not permitted by statutory regulation or exceeds the permitted use, you will need to obtain permission directly from the copyright holder. To view a copy of this license, visit http://creativecommons. org/licenses/by/4.0/.

(c) The Author(s) 2021 


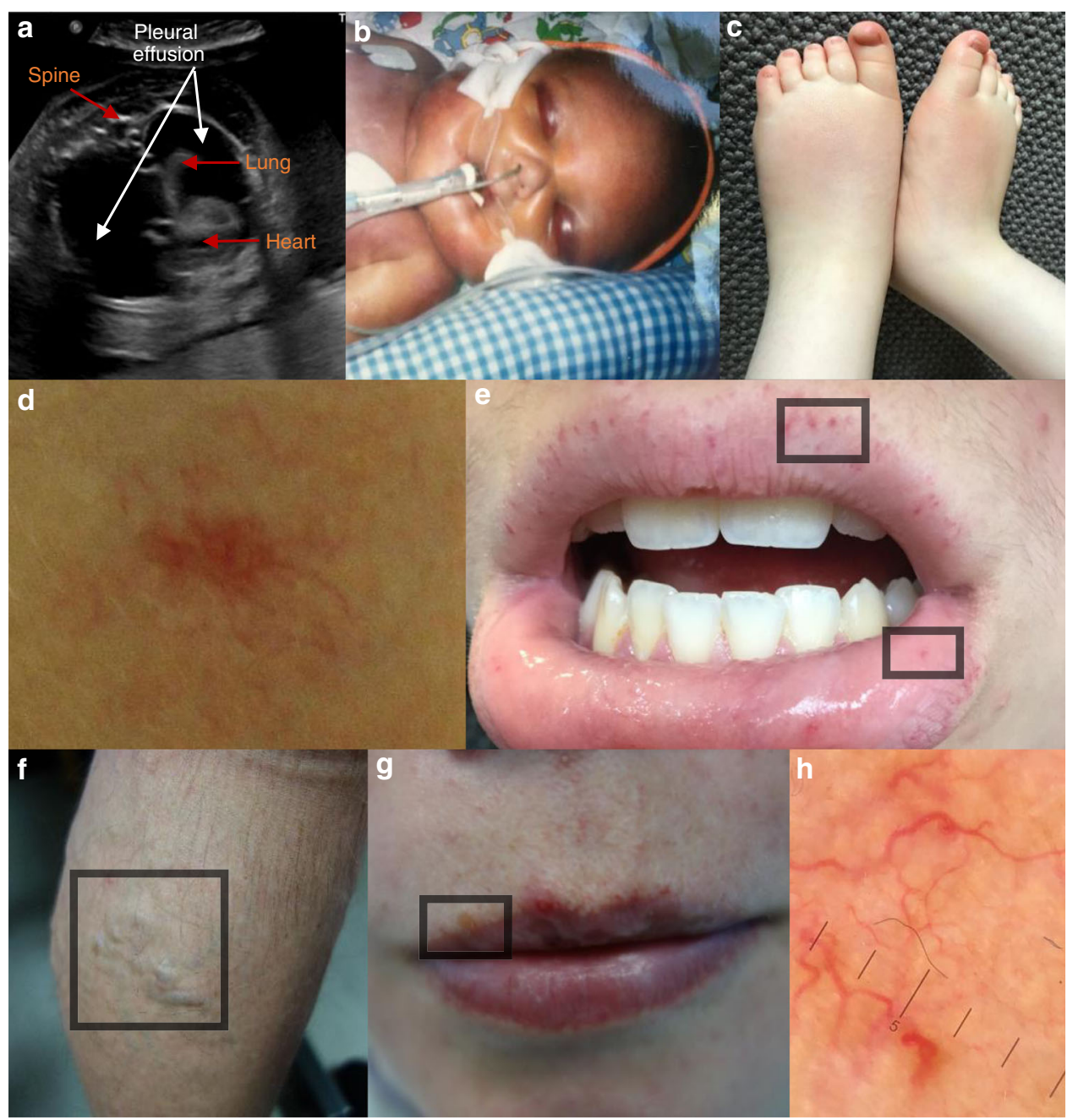

Fig. 1 Clinical findings in individuals with EPHB4 variants. (a) Antenatal ultrasound scan (transverse plane) demonstrating bilateral pleural effusions at gestational week $30+4$ in FH2:II.1. (b) Baby in the neonatal period with fetal hydrops (GLDUK:Il.6). (c) Persistent peripheral lymphedema in the feet of FH5:Il.2 at age 4 years. (d) Capillary malformation in the midline of the neck in VA1:Il.2. (e) Multiple telangiectasia along the vermilion border of the upper lip and the mucous membrane of the lower lip in VA2:II.1 (inside boxed areas). (f) Early onset and extensive lower limb varicose veins in GLDUK:I.2. (g) GLDUK:II.4 with multiple telangiectasia with a propensity for the vermilion border of the lips (inside boxed area). (h) Dermatoscopic image of telangiectasia on the left cheek confirming the presence of dilated linear and branching capillary vessels in GLDUK:II.4. 